\title{
The XXIV International Symposium on Morphological Sciences (ISMS 2015): worldwide Anatomy meets in Istanbul - a report*
}

\author{
Diogo Pais \\ Secretary-General ICSMS and President EFEM; Department of Anatomy, NOVA Medical School, Faculdade de Ciências Médicas, \\ Universidade NOVA de Lisboa, Lisboa, Portugal
}

If the world were but a single country, Istanbul would be its capital.

(Napoléon Bonaparte, 1769-1821)

The city of Istanbul, former Byzantium and Constantinople, one of the most beautiful and historically rich and significant capitals in the world, the gateway between East and West, was the ideal setting for the 24th International Symposium on Morphological Sciences.

A total of 398 registered participants, coming from 45 different countries (Figure 1) gathered at the Istanbul
University, Faculty of Science, Prof. Dr. Cemil Bilsel Congress Hall, between 2 and 6 September 2015. Hosted by the Turkish Society of Anatomy and Clinical Anatomy (TSACA), under the Presidency of Prof. Hakan Hamdi Çelik and Prof. Erdogan Şendemir (Figure 2) and organized by Burkon-Turizm\&Kongre, the meeting was a success and highly praised, for the quality of both its scientific and social program.

Included in the Scientific Program was a very informative and rich workshop entitled "Medical Photography -

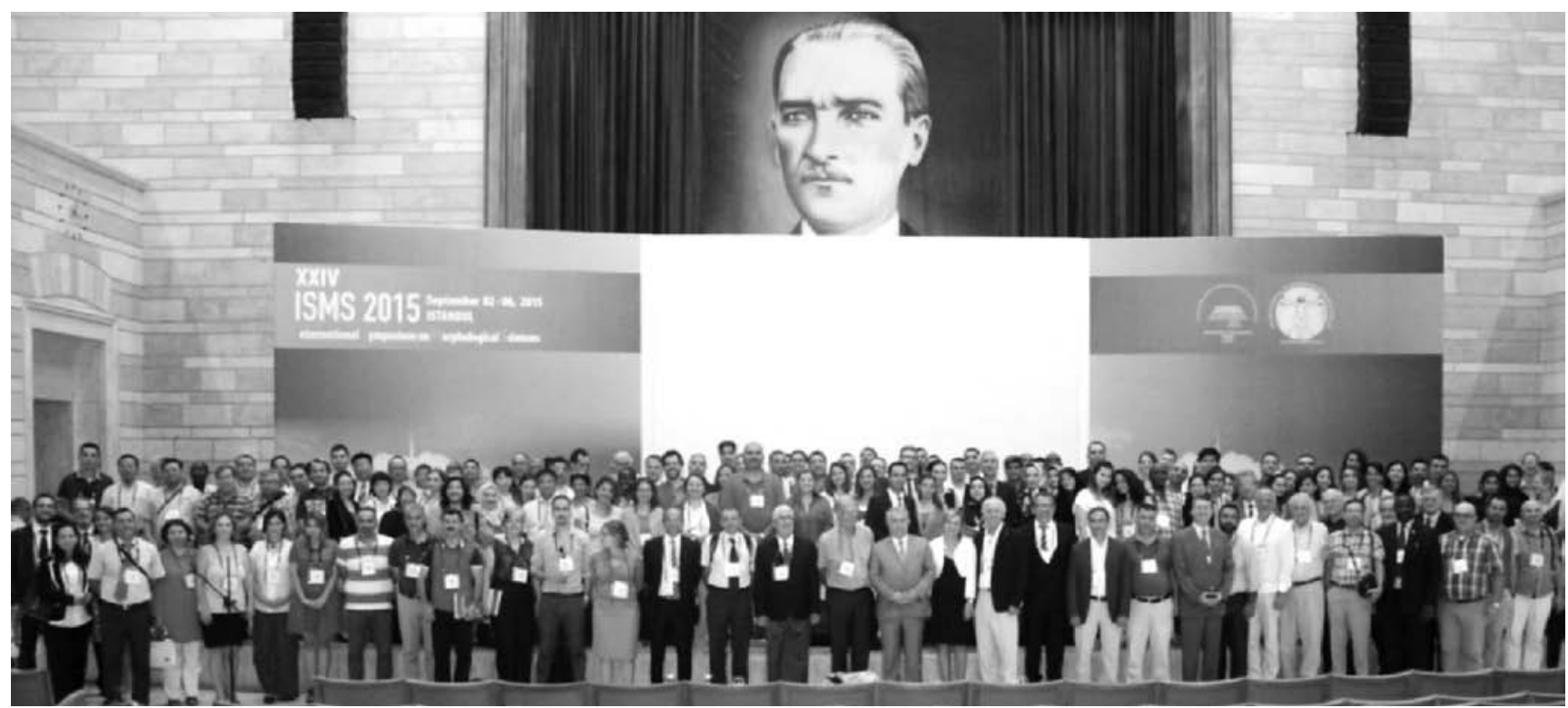

Figure 1. A group photo taken during the meeting in the main Congress Hall.

*Parts of this report are reprinted with permission from Medical fournal of West Kazakbstan 2015;3:31-3. 
Guidelines for Standard Photography in Gross and Clinical Anatomy".

There were 52 invited speakers, 11 of which delivered plenary lectures and the remaining 41 participated in thematic mini-symposia. A total of 99 oral presentations and 327 posters rounded up beautifully the very rich and scientifically sound program of the event.

The quality of the lecturers chosen should be stressed. For this meeting, the Organizing Committee decided to privilege the neuroanatomical sciences, which was a very successful choice. The opening lecture was presented by the prominent Swedish scientist, Prof. Sten Grillner, and was entitled 'The Evolutionary Logics of Networks - from Microcircuits to Selection of Behaviour'. The next day started with the 2015 EFEM Lecture, sponsored by the European Federation for Experimental Morphology, which was proficiently presented by the Turkish-born scientist, Prof. Reha S. Erzurumlu (Baltimore, USA), on the 'Midline Crossing of Sensory Pathways'. The EFEM Lecture was followed by two lectures: 'Ultrastructural Neuropathology in Transgenic Models of Alzheimer's Disease', presented by Prof. Alev Erisir (Virginia, USA) and 'Histopathological Changes in Animal Models of ALS', presented by Prof. Emel Ulupinar (Eskisehir, Turkey). At the same time, Prof. Ozan Akkus (Cleveland, USA) was presenting on Hall 2 the lecture 'Electrochemical Processing of Charged Molecules: Pathway to Engineering of Complex Tissue Structures'. Prof. George Paxinos (Sydney, Australia) then presented the lecture entitled 'Brain, Behaviour and Evolution'. September 4th started with the lecture by Prof. Tomas Hökfelt (Stockholm, Sweden) on 'Neuropeptides and Their Involvement in Pain and Depression', followed by Prof. Juan Mena Segovia (Oxford, UK) which spoke on 'Cholinergic Brainstem Modulation of Striatal Circuits: Multiple Levels of Synaptic Integration' and Prof. Gazi Yaşargil (Istanbul, Turkey) that talked about 'New Aspects in Neuroanatomy'. The final two excellent plenary lectures delivered during this congress, were the 'Misinterpreted White Matter Tracts of The Human Brain Revealed Through Fiber Dissection' by Prof. Uğur Türe (Istanbul, Turkey) and the 'Ultrastructural Morphology of White Matter Axons as a Function of Age and Ischaemia', presented by Prof. Selva Baltan (Cleveland, USA).

What stands out as a paradigm of the International Symposia on Morphological Sciences, bringing a wide variety and richness to the Scientific Program, is the inclusion of thematic mini-symposia, organized and chaired by prominent morphologists from around the world. In this meeting, the program included 11 mini-symposia, with a total of 48 presentations. The first two mini-symposia

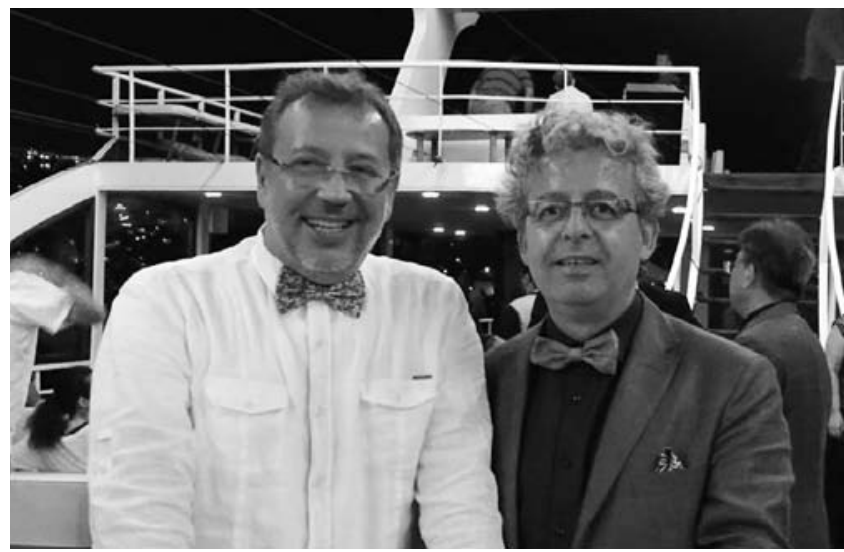

Figure 2. The presidents of the XXIV ISMS (left to right): Prof. Hakan Hamdi Çelik and Prof. Erdoğan Şendemir.

were sponsored by the Chinese Society of Anatomical Sciences (CSAS): 'Neuroanatomy' was chaired by Prof. Yun-Qing Li (Xi'an, China) and 'Histology and Embriology', chaired by Prof. Hong-Quan Zhang (Beijing, China). On September 4th we had the mini-symposium 'Clinical Anatomy - Translational Research', chaired by Prof. Stephen Carmichael (Mayo Clinic, USA), in the morning and 'Digital Sectional and Clinical Anatomy', chaired by Prof. Shao-Xiang Zhang (Chongqing, China), the 'Rapid Steroid Effects on the Brain', chaired by Prof. Gustav F. Jirikowski (FSU Jena, Germany) and by Prof. Jack D. Caldwell (VCOM, Spartanburg, USA), followed by 'Anatomy from Bench to Bedside', chaired by Prof. Gordana Teofilovski-Parapid (Belgrade, Serbia), Oladapo Ashiru (Lagos, Nigeria) and Susana Biasutto (Cordoba, Argentina). The final day of the congress had 5 mini-symposia: 'New Trends in Molecular and Biomedical Imaging, chaired by Prof. Diogo Pais (Lisbon, Portugal) and by Prof. Javier Regadera (Madrid, Spain), the mini-symposium 'To the Memory of Prof. Mauricio Moscovici' 'Recent Advances in Reproductive Biology', chaired by Prof. Guido Macchiarelli (L'Aquila, Italy), 'Biotechnology in Morphological Sciences', chaired by Prof. Gülgün Şengül (Izmir, Turkey), 'Cell Death and Autophagy', chaired by Prof. Yasuo Uchyiama (Tokyo, Japan) and finally the mini-symposium, sponsored by TEPARG/EFEM, 'Body Donation', chaired by Beat M. Riederer (Lausanne, Switzerland).

Since anatomists from all over the world attend International Symposia on Morphological Sciences, International Organizations and Committees usually choose to hold administrative meetings before and during the Symposia. In Istanbul, several administrative meetings were held in an extremely well equipped room: the Federative International Programme for Anatomical 
Terminologies (FIPAT-IFAA) met on August 31st and September 1st, chaired by Prof. John Fraher (Ireland); this was followed, during the Symposium, by the Executive Committee Meeting of the International Federation of Associations of Anatomists (IFAA), chaired by Prof. Beverley Kramer (South Africa), the special Council Meeting of the European Federation for Experimental Morphology (EFEM), chaired by Prof. Diogo Pais (Portugal) and the General Assembly of the International Committee of Symposia on Morphological Sciences, chaired by Prof. Guido Macchiarelli (Italy). Being officially responsible for the organization of all the International Symposia on Morphological Sciences, the ICSMS General Assembly was of special importance and even more, this year, because the Executive Board for the next five years' term (2016-2021) was elected: the former VicePresident, Prof. Gordana Teofilovsky-Parapid (Serbia), was appointed Honorary President, the new President is Prof. Guido Macchiarelli (Italy), the immediate PastPresident is Prof. Yasuo Uchyiama (Japan), the SecretaryGeneral is now Prof. Diogo Pais (Portugal), the new VicePresident is Prof. José Luis Bueno Lopez (Spain) and the new Secretary is Prof. Tatsuo Ushiki (Japan). New delegates were admitted unanimously, namely Prof. Nadir Prates as the new delegate of Brazil and Prof. Gulmira Zhurabekova and Prof. Yerbol Bekmuhambetov as the new delegates of Kazakhstan, which was a motive of great satisfaction for all the members and delegates present. One of the highlights of the ICSMS meeting was the presenta- tion of the Chinese application to organize the XXV ISMS. All those present in the meeting were unanimous to approve the candidature and it was, therefore, decided that the XXVth ISMS will be held in the beautiful city of Xi'an in China from July 27-30th, 2017, under the presidency of Prof. Yun-Qing Li, MD, PhD.

The Social Program presented a unique and exuberant opportunity for the participants to have a special taste of the hosting countries' Culture. On the Opening Ceremony, the beautiful piece 'Sunland Anatolia' was played on the piano by the Turkish composer and pianist Tuluyhan Uğurlu, illustrated by a very rich photographic presentation depicting the history and the landscape of beautiful Anatolia. As usual, the Gala Dinner was an occasion for a more informal and well-spirited gathering of the participants, cruising on a Bosphorus Boat (Figure 3), where tradition was kept and where the Secretary-General and newly elected President of the ICSMS for 2016-2021, Prof. Guido Macchiarelli, along with the other members of the Executive Board presented Prof. Yun-Qing Li, President of the XXVth ISMS, the symbolic ISMS/Symposia Morphologica flag and the medal where all the ISMS meetings' information (City, Year and Presidency) are engraved for posterity (Figure 4). The social program included a wide variety of congress and post-congress tours for accompanying persons and participants alike.

During this meeting, four awards were given: the Turkish Society of Anatomy and Clinical Anatomy offered

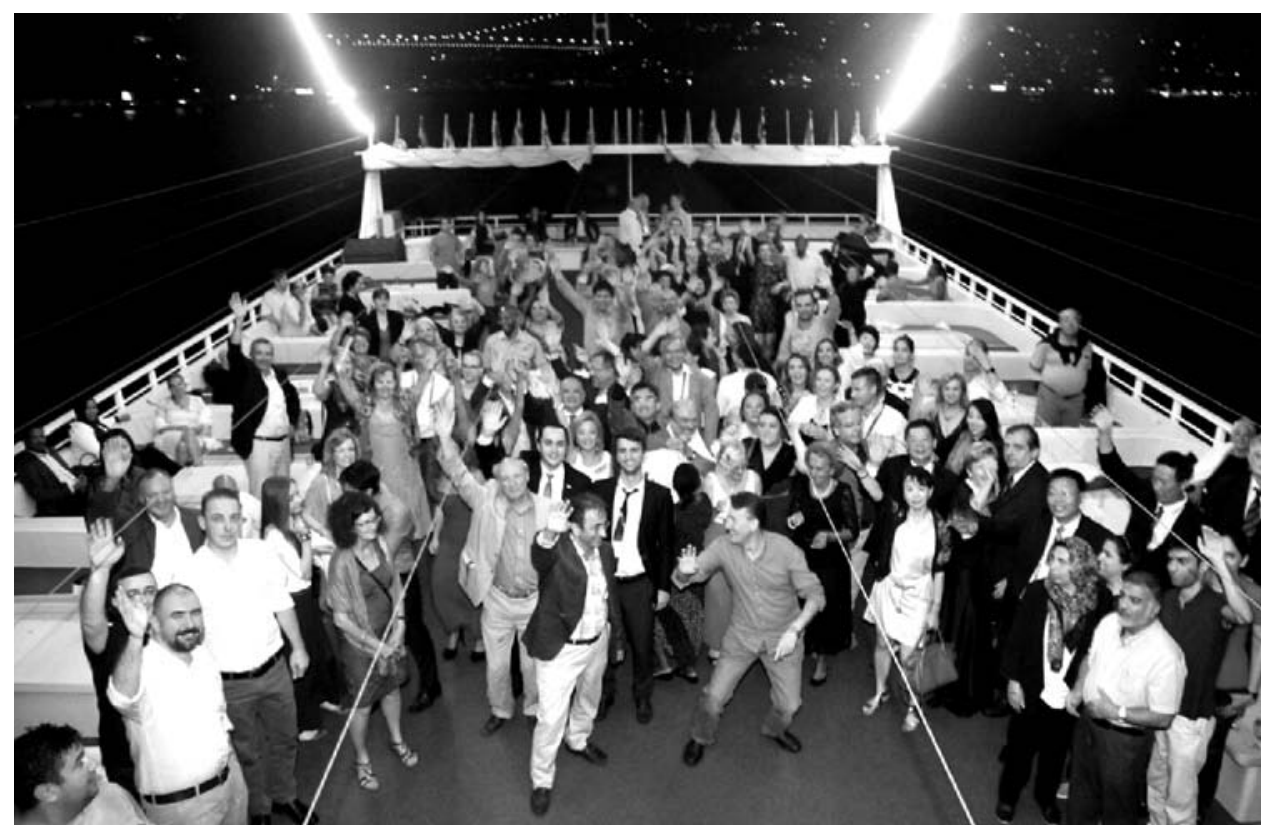

Figure 3. Participants cruising on a Bosphorus boat at the gala dinner of the XXIV ISMS. 


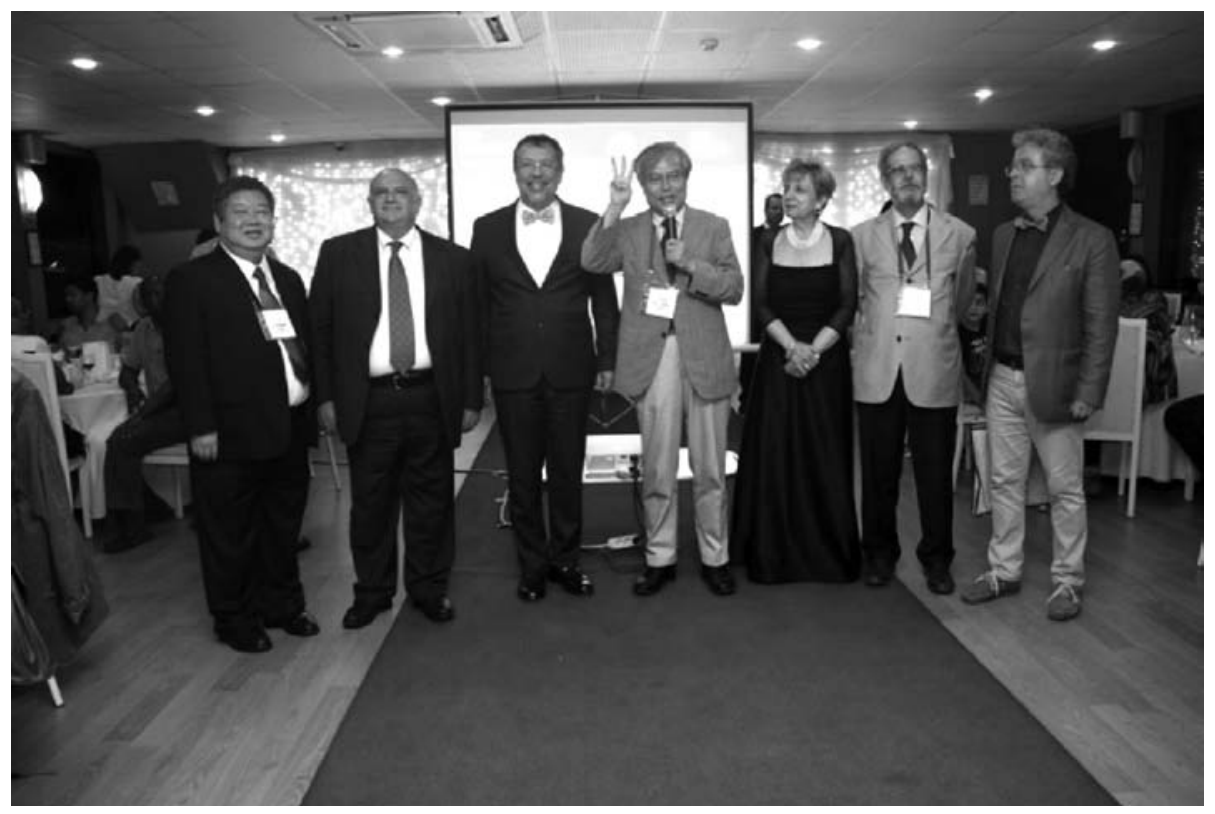

Figure 4. The President of ICSMS addressing the participants during the gala dinner (from left to right): Profs. Yun-Qing Li (China), Guido Macchiarelli (Italy), Hakan Hamdi Çelik (Turkey), Yasuo Uchyiama (Japan), Gordana Teofilovski-Parapid (Serbia), Diogo Pais (Portugal), and Erdogan Şendemir (Turkey).

two "Young Scientist" awards, after Prof. Dr. Atilla Müftüoğlu, to Özlem Sarıöz Kirazlı (Istanbul, Turkey), for her study "The effect of growth hormone on the 6OHDA model of Parkinson's disease" and to Maryam Soleimani (Tehran, Iran) for her study "Vitamin D3 influence the Th1/Th2 ratio in C57BL/6 in model of experimental autoimmune encephalomyelitis"; the ICSMS assigned its award for best presentation of the meeting to Dr. Christoph Köhler (Cologne, Germany), for his "Confocal microscopy analysis of granulovascular degeneration in transgenic mice"; during its General Assembly, the ICSMS conferred the 'Anatomist Excellence Award' to Prof. Diogo Pais (Lisbon, Portugal), for his outstanding contributions to morphological sciences, both at National and International levels, especially during the past 10 years.
The scientists, coming from all over the world, that gathered in Istanbul for the attendance of the XXIVth International Symposium on Morphological Sciences, left much richer, both scientifically and affectively, primarily as a result of the excellent organization of the meeting and the extremely high quality of the scientific work shared and secondly due to the warm welcome from our Turkish colleagues and to the friendly atmosphere which results from meeting again wonderful friends that share with us the same love for the morphological sciences. We left Istanbul with a feeling of gratitude and wishing to come back very soon. Gladly, we will not have to wait for long since there is the chance to come back in 2019 for the meeting of the International Federation of the Associations of Anatomists (IFAA). See you all in 2019!

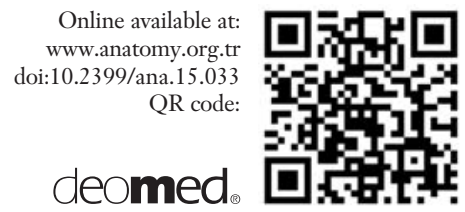

Correspondence to: Diogo Pais, MD, PhD

Department of Anatomy, NOVA Medical School, Faculdade de Ciências Medicas, Universidade NOVA de Lisboa, Campo dos Martires da Patria, 130 1169-056 Lisboa, Portugal Phone: +351 218803040 e-mail: diogo.pais@nms.unl.pt

Conflict of interest statement: No conflicts declared.

This is an open access article distributed under the terms of the Creative Commons Attribution-NonCommercial-NoDerivs 3.0 Unported (CC BY-NCND3.0) Licence (http://creativecommons.org/licenses/by-nc-nd/3.0/) which permits unrestricted noncommercial use, distribution, and reproduction in any medium, provided the original work is properly cited. Please cite this article as: Pais D. The XXIV International Symposium on Morphological Sciences (ISMS 2015): worldwide Anatomy meets in Istanbul - a report. Anatomy 2015;9(3):196-199. 